\title{
A handy measuring device
}

\author{
Michael SG Bell MD FRCSC FACS
}

\begin{abstract}
A new, simple, inexpensive, low technology technique for objective measuring of abductor pollicis brevis strength is presented. This is reliable and reproducible, and gives acceptable accuracy. It consists of a Chatillon $6 \mathrm{~kg}$ scientific scale, from which the hook and handle have been removed. The scale is placed in a $2 \mathrm{~cm}$ malleable retractor, $30 \mathrm{~cm}$ in length, which has been bent, with a small notch created at one end to hold the scale. This device allows muscle strength measurement to be made directly and reproducibly by pushing the patient's abducted thumb back to a neutral position, recording the force required to do so. If the edge of the retractor is always placed at the base of the thumbnail, accurate comparative serial measurements can be made.
\end{abstract}

Published articles $(1,2)$ evaluating the principle of abductor pollicis strength testing support the development of such an instrument, and the authors have found this particular device to be entirely satisfactory in clinical use in more than 3000 patients.

\section{REFERENCES}

1. Liu F, Carlson L, Watson HK. Quantitative abductor pollicis brevis strength testing: Reliability and normative values. J Hand Surg [Am] 2000;25:752-9.

2. Bigelow E, Bell MSG. Carpal tunnel syndrome: A new objective evaluation technique. Can J Plastic Surg 1998;6:99-103.

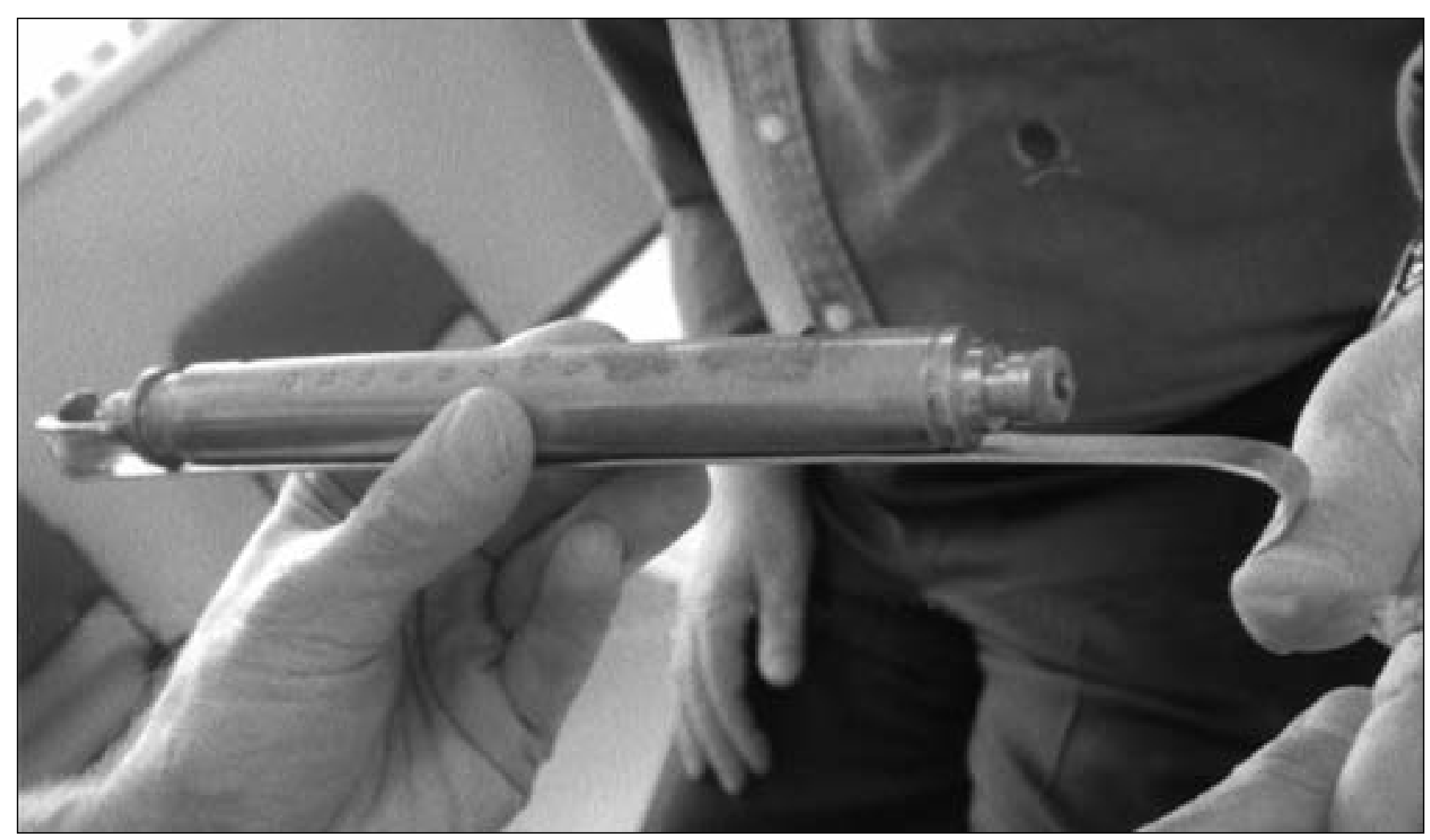

Figure 1) Abductor pollicis brevis strength tester

Department of Surgery, Division of Plastic Surgery, The Ottawa Hospital - Civic Campus, Ottawa, Ontario

Correspondence and reprints: Dr Michael SG Bell, 402-1919 Riverside Drive, Ottawa, Ontario K1H 1A2. Telephone 613-739-5424, fax 613-739-7168, e-mail msgbell@cyberus.ca 